\title{
Overexpression of MHC Class I in Muscle of Lymphocyte- Deficient Mice Causes a Severe Myopathy with Induction of the Unfolded Protein Response
}

\author{
Manuel Fréret, ${ }^{* \dagger}$ Laurent Drouot, ${ }^{* \dagger}$ Antoine Obry, ${ }^{* \dagger \S}$ Sandra Ahmed-Lacheheb, ${ }^{\dagger \ddagger \S}$ Claire Dauly, ${ }^{\circledR}$ Sahil Adriouch, ${ }^{* \dagger}$ \\ Pascal Cosette, ${ }^{\dagger \dagger \S}$ François-Jérôme Authier, $\|$ and Olivier Boyer ${ }^{* \dagger}$
}

\begin{abstract}
From the National Institute of Health and Medical Research (INSERM), U905, * Rouen; the Institute for Research and Innovation in Biomedicine, ${ }^{\dagger}$ Normandie University, Rouen; the National Center for Scientific Research (CNRS), ${ }^{\ddagger}$ UMR6270, Rouen; the Instrumental and Analytical Sciences Separative Platform of Rouen, ${ }^{\S}$ PISSARO, Rouen; Thermo Fisher Scientific, "Courtaboeuf; and INSERM, U955, "Créteil, France
\end{abstract}

\author{
Accepted for publication \\ June 4, 2013 \\ Address correspondence to \\ Olivier Boyer, M.D., Ph.D., \\ Inserm U905, Faculté de \\ Médecine et Pharmacie, 22 Bd \\ Gambetta, F-76000 Rouen, \\ France. E-mail: olivier.boyer@ \\ chu-rouen.fr.
}

\begin{abstract}
Muscle fibers do not normally express major histocompatibility complex class I (MHC-I) molecules, and their reexpression is a hallmark of inflammatory myopathies. It has been shown in mice that overexpression of MHC-I induces a poorly inflammatory myositis accompanied by the unfolded protein response (UPR), but it is unclear whether it is attributable to T-cell-mediated MHC-I-dependent immune responses or to MHC-I forced expression per se. Indeed, besides presenting antigenic peptides to $\mathrm{CD} 8^{+} \mathrm{T}$ cells, MHC-I may also possibly exert nonimmunologic, yet poorly understood pathogenic effects. Thus, we investigated the pathogenicity of MHC-I expression in muscle independently of its immune functions. HT transgenic mice that conditionally overexpress $\mathrm{H}-2 \mathrm{~K}^{\mathrm{b}}$ in muscle were bred to an immunodeficient Rag $^{-1-}$ background. The muscle proteome was analyzed by label-free high-resolution protein quantitation and Western blot. Despite the absence of adaptive immunity, HT Rag $2^{-/-}$mice developed a very severe myopathy associated with the cytoplasmic accumulation of $\mathrm{H}-2 \mathrm{~K}^{\mathrm{b}}$ molecules. The UPR was manifest by up-regulation of characteristic proteins. In humans, we found that HLA class I molecules not only were expressed at the sarcolemma but also could accumulate intracellularly in some patients with inclusion body myositis. Accordingly, the UPR was triggered as a function of the degree of HLA accumulation in myofibers. Hence, reexpression of MHC-I in normally negative myofibers exerts pathogenic effects independently of its immune function. (Am J Pathol 2013, 183: 893-904; http://dx.doi.org/10.1016/j.ajpath.2013.06.003)
\end{abstract}

Inflammatory myopathies (or myositis) encompass a group of severe acquired, subacute, or chronic diseases of skeletal muscle. They have been initially classified into three major entities $^{1,2}$ : polymyositis, an autoimmune disease mediated by oligoclonally expanded autoaggressive $\mathrm{CD}^{+} \mathrm{T}$ cells targeting as-yet unknown muscle autoantigens ${ }^{3,4}$; dermatomyositis, whose pathogenesis involves type I interferon pathways ${ }^{5}$; and inclusion body myositis (IBM), associated with intracellular protein inclusions and oligoclonal $\mathrm{CD} 8^{+}$ T-cell expansion. ${ }^{6-8}$ More recently, this classification has been enriched by isolating distinct entities, such as overlap myositis associated with extramuscular clinical features and/ or autoantibodies, ${ }^{9,10}$ anti-tRNA synthetase autoantibody syndrome, ${ }^{11,12}$ and autoimmune necrotizing myopathies ${ }^{13}$ with little inflammation but the presence of autoantibodies such as anti-signal recognition particle ${ }^{14}$ or statin-induced autoantibodies targeting 3-hydroxy-3-methylglutaryl coenzyme A reductase. ${ }^{15}$

One peculiar immunologic feature of myofibers is that they do not express detectable levels of major histocompatibility complex class I (MHC-I) molecules. In contrast, cultured myogenic precursors ${ }^{16}$ and regenerating myofibers from myopathic muscle show surface reexpression of MHC-I. ${ }^{17-20}$ Hence, surface MHC-I likely participates in the pathogenesis by presenting antigens to autoreactive

Supported by the Institut National de la Santé et de la Recherche Scientifique (INSERM), the University of Rouen, and the Fonds européen de développement régional (FEDER) program 33267.

Disclosure: C.D. is an employee of Thermo Fisher Scientific, which manufactures the Orbitrap apparatus used in this study. 
cytotoxic $\mathrm{CD}^{+}{ }^{+} \mathrm{T}$ cells. Nevertheless, MHC-I can also be expressed intracellularly ${ }^{21}$ and play multiple roles in myositis not only by antigen presentation but also through as-yet poorly understood, nonimmunologic processes. For example, forced expression of MHC-I was reported to attenuate muscle regeneration after injury. ${ }^{22}$

In IBM, histologic analysis typically shows surface MHC-I reexpression accompanying characteristic vacuolar degeneration and intracellular accumulation of $\beta$-amyloid precursor protein and phosphorylated tau, which has led to comparisons of IBM with Alzheimer disease. ${ }^{23}$ Although transcriptome analysis did not reveal truly distinctive molecular features of IBM compared with polymyositis, ${ }^{24}$ the view that nonimmunologic processes are active in IBM is supported by the lack of efficacy of corticosteroid and immunosuppressive therapy in contrast to polymyositis. ${ }^{25}$ To date, although IBM represents the most frequent form of myositis after age 50 years, most of its pathogenesis remains an enigma. ${ }^{26,27} \mathrm{It}$ is presumable that the toxicity induced by intracellular protein accumulation elicits muscle necrosis and subsequent fiber regeneration with MHC-I reexpression, which, in turn, allows $\mathrm{CD} 8^{+} \mathrm{T}$ cells to recognize newly presented muscle autoantigens. Conversely, a primary cytotoxic $\mathrm{CD}^{+} \mathrm{T}$-cell autoimmune response might lead to a myofiber assault, causing secondary intracellular accumulation of proteins.

Animal models have brought some insight into the pathogenesis of myositis. ${ }^{28,29}$ Experimental autoimmune myositis has been reported after immunization with muscle homogenates ${ }^{30}$ or purified antigens. ${ }^{31}$ Yet, mice expressing transgenic ovalbumin specifically in muscle do not develop myositis on immunization or even when crossed to ovalbumin-specific TCR-transgenic mice, in relation to the lack of muscle MHC-I expression. ${ }^{32-34}$ Mouse lines have been genetically engineered to overproduce different fragments of $\beta$-amyloid precursor protein, ${ }^{35-37}$ but no published animal models fully recapitulate IBM features. ${ }^{27}$ Diabetesprone NOD mice, when bred onto an $\mathrm{ICOS}^{-/}$or ICOS$L^{-1-}$ background, do not develop diabetes but a myositis that is accompanied by an autoimmune neuropathy. ${ }^{38} \mathrm{SJL} / \mathrm{J}$ mice spontaneously develop myositis, but they harbor a mutation in the dysferlin gene and, therefore, represent a model of genetic dysferlinopathy rather than of myositis. ${ }^{39}$ In TRE-H-2 $\mathrm{K}^{\mathrm{b}} \mathrm{x}$ mck-tTA (HT) transgenic mice, in which it is possible to conditionally induce production of the MHC-I $\mathrm{H}-2 \mathrm{~K}^{\mathrm{b}}$ molecule in myofibers, $\mathrm{H}-2 \mathrm{~K}^{\mathrm{b}}$ overexpression causes a severe, yet poorly inflammatory myopathy. ${ }^{40}$ Muscles of these mice display moderate macrophage and almost no lymphocytic infiltrates. It is unknown in this model whether the disease can be transferred by $\mathrm{T}$ cells, and it was shown recently that the muscle deficiency occurs before any muscle mononuclear infiltrate. ${ }^{41}$ Therefore, the pathogenic role of immune cells as opposed to possible nonimmunologic effects of MHC-I expression remains uncertain. It has been suggested that the development of endoplasmic reticulum (ER) stress and the unfolded protein response (UPR) may participate in the pathogenesis of myopathy in HT mice. ${ }^{42,43}$
It remains to be determined what is attributable to T-cellmediated MHC-I-dependent immune responses or to MHC-I forced expression per se. It must be determined whether MHC-I overexpression alone is sufficient to induce the UPR and a symptomatic myopathy in the absence of contribution of muscle-specific T-cell responses directed against putative antigenic peptides presented by transgenic $\mathrm{H}-2 \mathrm{~K}^{\mathrm{b}}$. We postulate herein that nonimmune mechanisms contribute to the pathogenicity of MHC-I overexpression independently of the capacity of these molecules to present antigenic peptide to T cells, and we investigated this issue in HT mice rendered devoid of an adaptive immune system.

\section{Materials and Methods}

\section{Mice}

TRE-H- $2 \mathrm{~K}^{\mathrm{b}} \mathrm{x}$ mck-tTA, referred to as HT mice, were a gift from Kanneboyina Nagaraju (National Institute of Arthritis and Musculoskeletal and Skin Diseases, NIH, Bethesda, MD). ${ }^{40}$ Overexpression of MHC-I heavy chain is induced from an $\mathrm{H}-2 \mathrm{~K}^{\mathrm{b}}$ transgene under the control of a tetracyclineresponsive element activated by a muscle-expressed tetracycline transactivator tTA (tet-off system). Muscle-specific transgene expression is effective after the removal of doxycycline (Dox) from drinking water. HT mice were crossed to a $\mathrm{Rag} 2^{-/-}$background to generate HT Rag $2^{-/-}$ mice. Pregnant and lactating mothers were given oral Dox. $\mathrm{H}-2 \mathrm{~K}^{\mathrm{b}}$ expression was induced by Dox removal at weaning (day 28). The protocol was approved by an institutional ethics committee (Comité Régional d'Ethique en Expérimentation Animale, University of Rouen, Rouen, France).

\section{Muscle Evaluation}

The scoring system was as follows: 0 , normal motility; 1 , moderate decrease in locomotive activity and dawdling tail; and 2, severe decrease in locomotive activity and hunched back. For the grip strength test (BioSeb, Chaville, France), mice were lifted carefully by the tail so that their four paws grasped a grid connected to an isometric force transducer. The maximal force before losing grip was computed as the mean of at least five measurements per mouse.

\section{Histologic Analysis}

Mouse muscles were dissected immediately after euthanasia, snap frozen in liquid nitrogen, and cut into $8-\mu \mathrm{m}$ sections. Staining was performed using H\&E or Gomori trichrome. For immunofluorescence analysis, after preincubation with $1 \%$ fetal calf serum, frozen sections were stained with anti- $\mathrm{H}-2 \mathrm{~K}^{\mathrm{b}}$ (clone AF6-88.5; BD Pharmingen, San Diego, CA), anti$\alpha \mathrm{B}$-crystallin (NCL-abCRYS-512, clone p3-NS1-Ag4-1; Novocastra, Leica Microsystems Inc., Buffalo Grove, IL), or anti-caveolin (sc5310; Santa Cruz Biotechnology, Santa Cruz, CA) mouse monoclonal antibodies, followed by revelation 

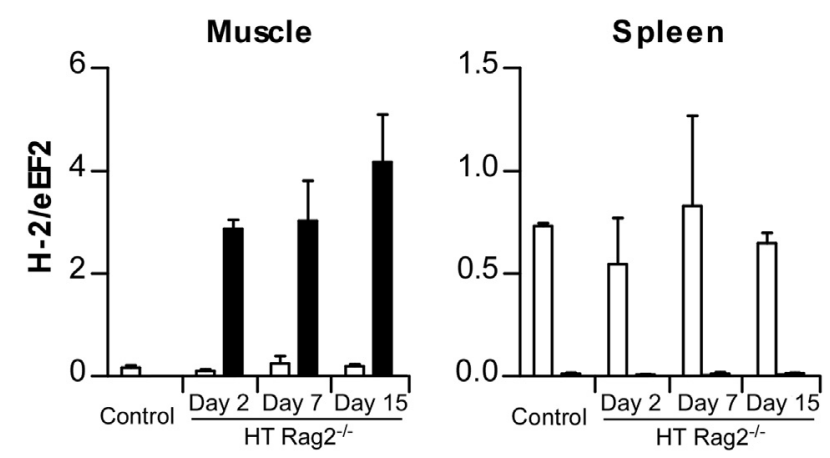

Figure 1 Up-regulation of transgenic $\mathrm{H}-2 \mathrm{~K}^{\mathrm{b}}$ in muscle of $\mathrm{HT} \mathrm{Rag}^{-/}-$ mice. mRNA level of endogenous $\mathrm{H}-2 \mathrm{D}^{\mathrm{b}}$ (white bars) and transgene-specific $\mathrm{H}-2 \mathrm{~K}^{\mathrm{b}}\left(\mathrm{H}-2 \mathrm{~K}^{\mathrm{b}} \mathrm{Tg}\right.$; black bars) in quadriceps femoris muscle and spleen of HT $\operatorname{Rag}^{-{ }^{-}}$mice ( $n=3$ at each time point) determined by quantitative RT-PCR (data were normalized to the level of eEF2 expression). Control mice were TRE-H-2 $\mathrm{K}^{\mathrm{b}}$ Rag2 $^{-1}$ - single $\mathrm{Tg}$ mice $(n=3)$. Days refer to time since Dox removal. Data are shown as means $\pm \mathrm{SE}$ of the relevant $\mathrm{H}-2$ gene ratios.

using a rabbit anti-mouse IgG secondary antibody coupled to Alexa Fluor 647 (A-21239; Invitrogen, Carlsbad, CA) or a donkey anti-mouse IgG secondary antibody coupled to Cy3 (715-166-150; Jackson ImmunoResearch Laboratories, West Grove, PA) and Hoechst counterstaining. For neonatal myosin heavy chain (nMyHC) staining, serial $8-\mu$ m cryosections were incubated alternatively with an anti-nMyHC (ab49461; Abcam Inc., Cambridge, MA) or an anti-HLA-I (anti-human HLA-ABC, MO736, clone W6/32; Dako, Carpinteria, CA) mouse monoclonal antibody and were further revealed with a Cy3- or Cy5-labeled secondary anti-mouse Ig antibody. Controls for staining specificity (omission of the primary antibody or use of nonimmune normal mouse serum, 015.000.002; Jackson ImmunoResearch Laboratories) were always negative. For electron microscopy, after staining with
$4 \%$ uranyl acetate then lead citrate, ultrathin $(1-\mu \mathrm{m})$ sections were examined by using a Tecnai 12 transmission electron microscope (FEI, Eindhoven, The Netherlands).

In parallel, MHC-I immunostaining was performed on muscle biopsy sampling from patients with IBM. The diagnosis of IBM was established according to accepted criteria, ${ }^{8}$ including histologic analysis by an experienced pathologist. Controls were histologically normal muscles obtained through a routine diagnostic procedure. They were devoid of any morphologic abnormality. In particular, we checked for the complete lack of myofiber necrosis/regeneration feature, inflammation, and myofiber MHC-I reexpression in selected muscles. Patients were stratified using a semiquantitative method according to the number of fibers positive for intracellular HLA-I staining: 0 , absent; *, $<50 \%$; **, $50 \%$ to $80 \%$; and $* * *,>80 \%$. The intensity of this intracellular MHC-I staining was typically heterogeneous. Immunoperoxidase assay was performed on 8 - $\mu \mathrm{m}$ cryosections with a mouse monoclonal antihuman HLA-ABC antibody (M0736, clone W6/32; Dako), followed by revelation with diaminobenzidine as substrate using a Leica BOND-III automated stainer (Leica Microsystems Inc.). Image capture was performed using a Nikon Coolscope digital microscope (Nikon Instruments, Melville, NY).

\section{Real-Time PCR}

Total RNA was extracted using TRIzol (Invitrogen) from homogenized frozen quadriceps femoris muscle, and $1 \mu \mathrm{g}$ was reverse transcribed. Primers (forward and reverse) were specific for mouse CHOP, 5'-GCATGAAGGAGAAGGAGCAG- $3^{\prime}$ and 5'-CTTCCGGAGAGACAGACAGG-3'; eEF2, 5'-AAGCTGATCGAGAAGCTGGA-3' and 5'-CCCCTCGTATAGCAGCTCAC-3'; H-2D ${ }^{\mathrm{b}}, 5^{\prime}$-GGTGCTG-
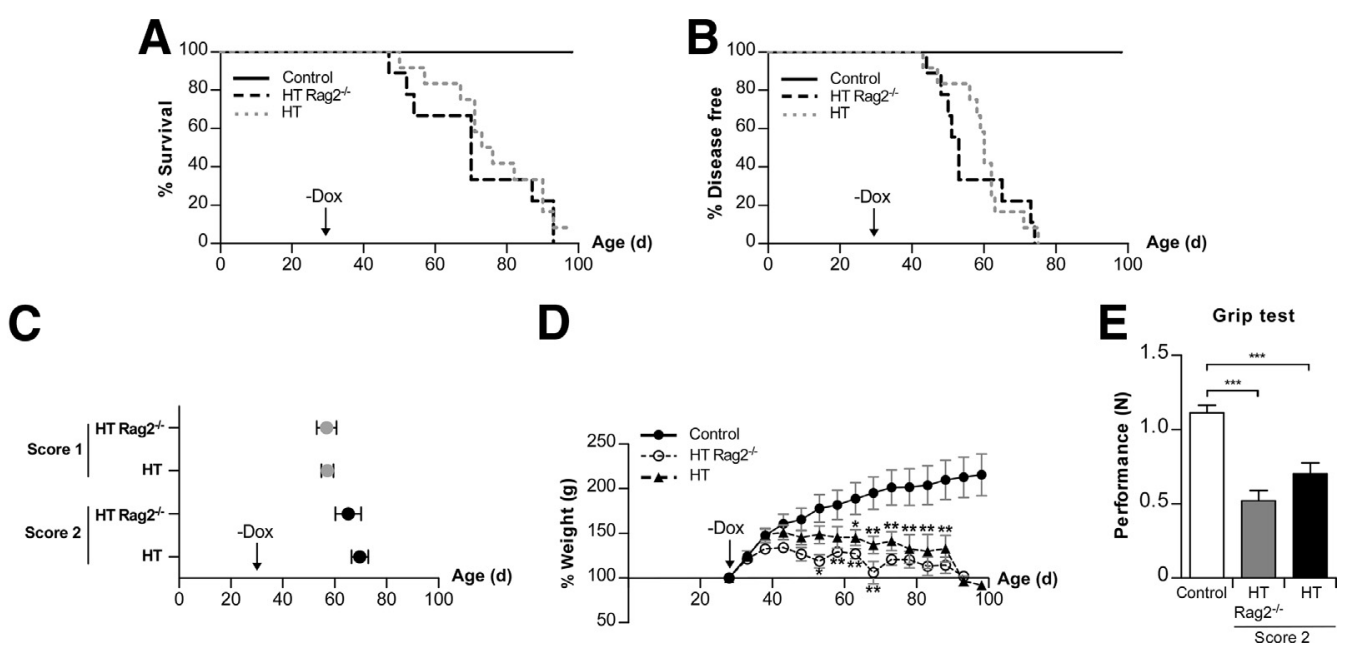

Figure 2 Forced expression of $\mathrm{H}-2 \mathrm{~K}^{\mathrm{b}}$ in muscle provoked severe myopathy in immunodeficient mice. A: Kaplan-Meier curve of overall survival. Day 0 was the day of birth. Dox was removed at weaning (day 28 of life) for HT $(n=12)$ and HT $\operatorname{Rag}^{-/-}(n=9)$ mice. Controls were TRE-H-2K ${ }^{\mathrm{b}}$ single Tg mice $(n=11)$. Groups ( $\mathrm{HT}$ and $\mathrm{HT} \mathrm{Rag2^{-/- }}$ ) were compared with controls using the log-rank test $(P<0.0001)$. B: Kaplan-Meier curve of disease-free survival. Mice

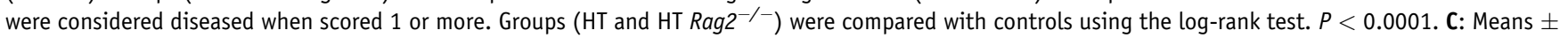
SE days before the onset of clinical signs (score 1) or severe disease (score 2). Data were compared using Student's $t$-test. D: Weight curves. Data are means \pm SE of weight with reference to the weight at the day of Dox removal. Groups (HT and HT Rag2 ${ }^{-1}$ ) were compared with controls using Student's $t$-test. ${ }^{\star} P<0.05,{ }^{* *} P<0.01$, and ${ }^{* * *} P<0.001$. E: Grip strength in score 2 -diseased HT $(n=10)$ and score 2 -diseased HT Rag2 ${ }^{-/-}(n=9)$ mice compared with controls $(n=11)$. Means \pm SE results were compared using Student's $t$-test. 
CAGAGCATTACAA- ${ }^{\prime}$ and $5^{\prime}$-AGGGTGATGTCAGCAGGGTA-3'; H-2 $\mathrm{K}^{\mathrm{b}}$ (transgenic but not endogenous), $5^{\prime}$ GAGGAGCTGATCCAGGACAT- $3^{\prime}$ and $5^{\prime}$-TGTTGGAGACAGTGGATGGA-3'; spliced XBP1s, 5'-GAGTCCGCAGCAGGTG- $3^{\prime}$ and $5^{\prime}$-GTGTCAGAGTCCATGGGA-3'; and unspliced XBP1u, 5'-AAGAACACGCTTGGGAATGG- $3^{\prime}$ and $5^{\prime}$-ACTCCCCTTGGCCTCCAC- $3^{\prime}$. For real-time $\mathrm{PCR}$, all the samples were run in triplicate using SYBR Green.

\section{Immunoblot Analysis}

Quadriceps femoris and tibialis anterior muscles were snap frozen in liquid nitrogen, ground in a mortar, and homogenized in ice-cold radioimmunoprecipitation assay buffer supplemented with a protease inhibitor. Homogenates were then centrifuged at $16,000 \times g$ for 30 minutes at $4^{\circ} \mathrm{C}$. The protein concentration of supernatant was quantified using the bicinchoninic acid kit (Pierce Biotechnology, Rockford, IL). Lysates were further solubilized in NuPAGE lithium dodecyl sulfate sample buffer (Invitrogen) and were boiled for 10 minutes before SDS-PAGE. Protein (10 to $20 \mu \mathrm{g}$ ) was loaded and resolved on 12\% SDS-PAGE gels. After electrophoretic separation at $200 \mathrm{~V}$ for 1 hour, proteins were transferred to a polyvinylidene difluoride membrane (TransBlot; Bio-Rad Laboratories, Hercules, CA) at $30 \mathrm{~V}$ for 90 minutes. Membranes were then incubated in a blocking buffer (Odyssey; Li-Cor Biosciences, Lincoln, NE) with PBS containing $0.1 \%$ Tween. Subsequently, membranes were incubated in a blocking buffer (Odyssey) and then with one of the following antibodies: mouse anti- $\alpha \mathrm{B}$-crystallin (Stressgen; Enzo Life Sciences Inc., Farmingdale, NY), rabbit anti-ATF6 (LifeSpan BioSciences Inc., Seattle, WA), goat anti-BiP (Santa Cruz Biotechnology), rabbit anticalnexin (Santa Cruz Biotechnology), rabbit anti-LC3B recognizing LC3-I and LC3-II (Sigma-Aldrich, St. Louis, MO), rabbit anti-ovalbumin (RayBiotech Inc., Norcross, GA), rabbit anti-tTA Tet repressor (Pierce Biotechnology), or rabbit anti-glyceraldehyde-3-phosphate dehydrogenase (GAPDH) (Sigma-Aldrich) after washing with an appropriate Alexa Fluor 680-labeled secondary antibody (Invitrogen). Membranes were scanned using a Li-Cor scanner (Odyssey), and bands were quantified. Results are reported relative to GAPDH. A value of 1 was arbitrarily assigned to the control, which was used as a reference for other samples.

\section{Liquid Nanochromatography and Mass Spectrometry}

For mass spectrometric (MS) analyses, peptides were dissolved in $0.1 \%$ formic acid in water. All the experiments were performed with a linear ion trap Orbitrap mass spectrometer (LTQ Orbitrap Velos; Thermo Scientific, Bremen, Germany) equipped with a nano-electrospray ionization source and coupled to a nanoliquid chromatograph (Easy-nLC II; Thermo Scientific). The sample was loaded onto the enrichment column (Cap Trap C8, $0.5 \times 2 \mathrm{~mm}$; Bruker-Michrom, Auburn, CA) at a pressure of 200 bar in $0.1 \%$ formic acid. The separation was performed using a reversed-phase column $(\mathrm{C} 18, \mathrm{~L} 153$, internal diameter 5 $\mu \mathrm{m}, 100-\AA ̊$ pore size; Nikkyo Technos, Tokyo, Japan). The liquid chromatography gradient (mobile phase $\mathrm{A}: \mathrm{H}_{2} \mathrm{O} / 0.1 \%$ formic acid; mobile phase B: acetonitrile $/ 0.1 \%$ formic acid) was delivered at a flow rate of $300 \mathrm{~nL} / \mathrm{min}$. Tryptic peptides were eluted from the reversed-phase column into the mass spectrometer using a linear gradient of $15 \%$ to $40 \%$ of B mobile phase over 120 minutes. The capillary voltage was set at $1.5 \mathrm{kV}$; the source temperature was $200^{\circ} \mathrm{C}$.

The mass spectrometer was operated in the data-dependent mode to automatically switch between Orbitrap-MS and LTQ-MS/MS acquisition. Survey full scan mass spectra (from $\mathrm{m} / \mathrm{z} 300$ to 2000) were acquired in the Orbitrap with a resolution of $r=30,000$. The mass spectrometer selected
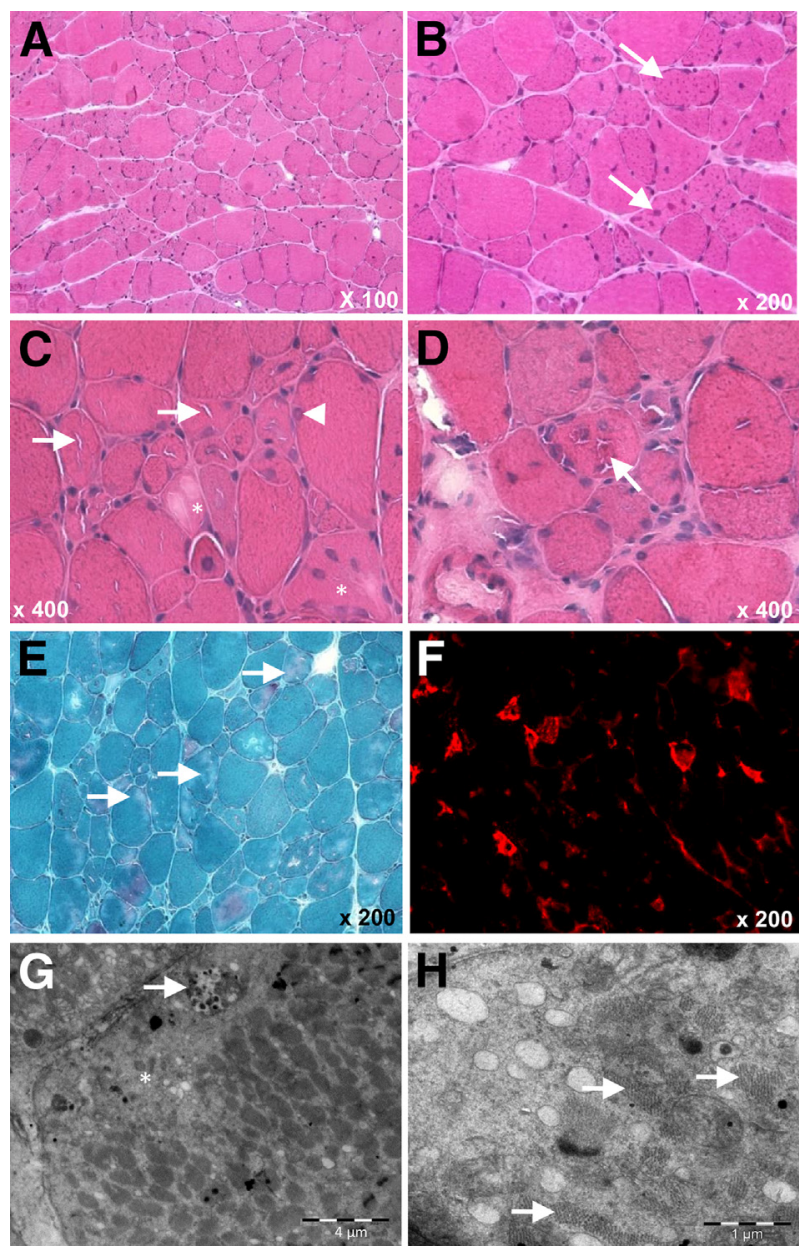

Figure 3 Histopathologic features of $\mathrm{H}-2 \mathrm{~K}^{\mathrm{b}}$-induced myopathy. A-D: Staining for morphologic assessment by standard H\&E. B: Intermyofibrillar accumulations (arrows). C: Intranuclear eosinophilic inclusion (arrowhead), linear rimmed vacuoles (arrows), and proteolysis foci (asterisks). D: Cytoplasmic body (arrow). E: Gomori's trichrome. Arrows, myofilamentous degradation. F: Fluorescence microscopy after in vivo injection of Evans blue dye. G and H: Electron microscopy. G: Accumulation of proteinlike material (asterisk) and an autophagic vacuole (arrow). H: Myofilament debris (arrows). Data are from the analysis of muscle frozen sections from score 2-diseased mice $(n=2$ to 3$)$ : quadriceps femoris (A, B, and F), paraspinal (C), semitendinosus/semimembranosus (D), and gastrocnemius (E). 
Table 1 High-Resolution Quantitation of Overexpressed Proteins

\begin{tabular}{|c|c|c|c|c|c|}
\hline \multirow[b]{2}{*}{ Overexpressed protein (diseased mice vs controls) } & \multirow[b]{2}{*}{ Symbol } & \multicolumn{2}{|c|}{$\begin{array}{l}\text { Average normalized } \\
\text { abundance }\end{array}$} & \multirow[b]{2}{*}{ Fold } & \multirow[b]{2}{*}{ ANOVA ( $P$ value) } \\
\hline & & HT Rag2 $^{-/-}$ & Control & & \\
\hline Lysyl-tRNA synthetase & SYK & 4477 & 0 & NA & 0.00007 \\
\hline Ubiquitin-like modifier-activating enzyme 5 & UBA5 & 3587 & 0 & NA & 0.00022 \\
\hline Loss of heterozygosity $11 \mathrm{chr}$ region 2 gene A protein homolog & LHR2A & 2199 & 0 & NA & 0.00016 \\
\hline Ubiquitin thioesterase 0TUB1 & 0TUB1 & 1957 & 0 & NA & 0.00001 \\
\hline Mitogen-activated protein kinase kinase kinase MLT & MLTK & 1790 & 0 & NA & 0.00009 \\
\hline Ras-related protein R-Ras2 precursor & RRAS2 & 1632 & 0 & NA & 0.00005 \\
\hline UPF0411 protein KIAA0157 & K0157 & 1347 & 0 & NA & 0.00019 \\
\hline Peroxisomal membrane protein PEX14 & PEX14 & 751 & 0 & NA & 0.00023 \\
\hline Coatomer subunit delta & COPD & 490 & 0 & NA & 0.00001 \\
\hline Leukocyte elastase inhibitor A & ILEUA & 450 & 0 & NA & 0.00003 \\
\hline Glycyl-tRNA synthetase & SYG & 11900 & 20 & 605 & 0.00003 \\
\hline Septin-9 & SEPT9 & 641 & 1 & 521 & 0.00033 \\
\hline Calreticulin precursor & CALR & 6298 & 25 & 253 & 0.00003 \\
\hline Cytoplasmic dynein 1 intermediate chain 2 & DC1I2 & 13500 & 64 & 213 & 0.00001 \\
\hline Heat shock protein $75 \mathrm{kd}$. mitochondrial precursor & TRAP1 & 2268 & 18 & 129 & 0.00013 \\
\hline H-2 class I histocompatibility antigen, K-B alpha chain precursor & HA1B & 22600 & 180 & 126 & 0.00023 \\
\hline Vacuolar ATP synthase catalytic subunit A & VATA & 15600 & 187 & 83 & 0.00008 \\
\hline Laminin subunit alpha-2 precursor & LAMA2 & 4026 & 50 & 81 & 0.00031 \\
\hline Src substrate cortactin & SRC8 & 972 & 15 & 66 & 0.00001 \\
\hline $78 \mathrm{kd}$ glucose-regulated protein precursor & GRP78 & 377000 & 8164 & 46 & 0.00002 \\
\hline Cathepsin D precursor & CATD & 61500 & 1791 & 34 & 0.00023 \\
\hline Polypyrimidine tract-binding protein 1 & PTBP1 & 1144 & 33 & 34 & 0.00020 \\
\hline BAG family molecular chaperone regulator 3 & BAG3 & 14600 & 448 & 33 & 0.00002 \\
\hline $14-3-3$ protein theta & $1433 \mathrm{~T}$ & 2660 & 88 & 30 & 0.00034 \\
\hline 3-ketoacyl-CoA thiolase A. peroxisomal precursor & THIKA & 11600 & 395 & 29 & 0.00015 \\
\hline Hypoxanthine-guanine phosphoribosyltransferase & HPRT & 8223 & 338 & 24 & 0.00020 \\
\hline Mannose-1-phosphate guanyltransferase alpha & GMPPA & 3818 & 157 & 24 & 0.00022 \\
\hline Filamin-C & FLNC & 20300 & 855 & 24 & 0.00018 \\
\hline Protein disulfide-isomerase A4 precursor & PDIA4 & 22900 & 1042 & 22 & 0.00026 \\
\hline Mitochondrial-processing peptidase subunit $\beta$, mitochondrial precursor & MPPB & 1200 & 60 & 20 & 0.00006 \\
\hline Protein-arginine deiminase type-2 & PADI2 & 19000 & 1010 & 19 & 0.00011 \\
\hline Bifunctional aminoacyl-tRNA synthetase & SYEP & 1268 & 74 & 17 & 0.00036 \\
\hline Lamin-A/C & LMNA & 80600 & 5006 & 16 & 0.00010 \\
\hline Nuclear distribution protein nudE homolog 1 & NDE1 & 292 & 19 & 15 & 0.00012 \\
\hline Actin-related protein 2 & ARP2 & 17100 & 1278 & 13 & 0.00006 \\
\hline Profilin-1 & PROF1 & 150000 & 11600 & 13 & 0.00018 \\
\hline Tubulin beta- 6 chain & TBB6 & 20500 & 1883 & 11 & 0.00037 \\
\hline Histone $\mathrm{H} 2 \mathrm{~B}$ type $1-\mathrm{B}$ & $\mathrm{H} 2 \mathrm{~B} 1 \mathrm{~B}$ & 1419 & 130 & 11 & 0.00027 \\
\hline Protein disulfide-isomerase A3 precursor & PDIA3 & 30300 & 3617 & 8.4 & 0.00016 \\
\hline Heat shock cognate 71 kd protein & HSP7C & 124000 & 16600 & 7.5 & 0.00021 \\
\hline Putative ATP-dependent RNA helicase Pl10 & $\mathrm{DDX} 3 \mathrm{~L}$ & 15400 & 2811 & 5.5 & 0.00014 \\
\hline Thioredoxin-like protein 1 & TXNL1 & 12000 & 2199 & 5.5 & 0.00019 \\
\hline Macrophage-capping protein & CAPG & 16300 & 3232 & 5.0 & 0.00008 \\
\hline Stress-induced-phosphoprotein 1 & STIP1 & 22200 & 5989 & 3.7 & 0.00025 \\
\hline Glyoxalase domain-containing protein 4 & GLOD4 & 1540 & 559 & 2.8 & 0.00027 \\
\hline
\end{tabular}

High-resolution quantitation (Orbitrap) of score 2-diseased HT Rag2 ${ }^{-/-}$mice $(n=3)$ muscle proteome. Data are protein fold increase compared with age-matched $\operatorname{Rag}^{-1-}$ controls $(n=2)$.

ANOVA, analysis of variance; NA, not applicable.

the 20 most intense ions for fragmentation. Target peptides already selected for MS/MS were dynamically excluded for 30 seconds. General MS conditions for selection were as follows: ion selection threshold, 500 counts for MS/MS; activation $Q$ value, 0.25 ; and activation time, $10 \mathrm{~ms}$ and were applied for MS/MS.

\section{Label-Free Peptide Quantification}

Raw data were imported into Progenesis LC-MS software version 4.0.4441.29989 (Nonlinear USA Inc., Durham, $\mathrm{NC})$. One sample was set as a reference, and the retention times of all the other samples in the experiment were 

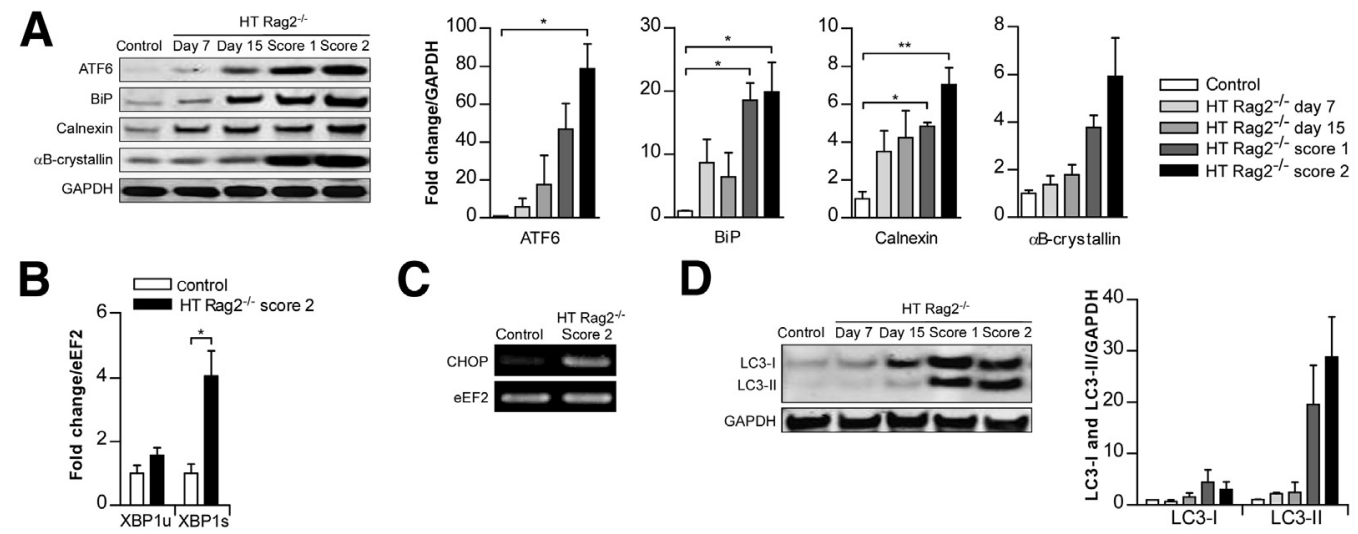

D
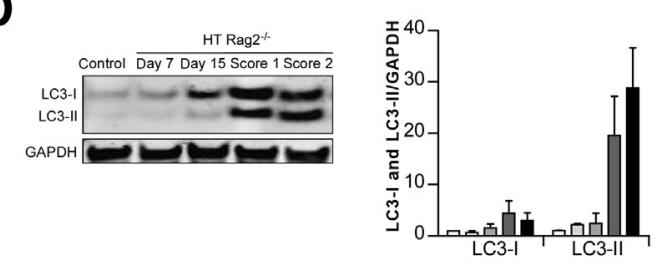

Figure 4 Forced expression of $\mathrm{H}-2 \mathrm{~K}^{\mathrm{b}}$ induced ER stress. A: Western blot analysis of ATF6, BiP, calnexin, and $\alpha \mathrm{B}$-crystallin in muscle 7 or 15 days after Dox removal and in score 1 - and score $2-$ diseased $\mathrm{HT}$ Rag $^{-/-}$mice. One of three reproducible Western blots and quantification of means \pm SE protein expression levels are shown. A value of 1 was arbitrarily assigned to control conditions to which GAPDH were reported and expressed as fold change. Groups were compared with controls using Student's $t$-test. ${ }^{*} P<0.05,{ }^{*} P<0.01$. B: Quantitative RT-PCR analysis of quadriceps femoris mRNA levels for unspliced XBP1u and spliced XBP1s transcripts of score $2-$ diseased HT Rag2 ${ }^{-1-}(n=3)$ and control Rag2 $^{-{ }^{-}}(n=3)$ mice. Data are means \pm SE fold change of the XBP1/eEF2 ratio. C: RT-PCR analysis

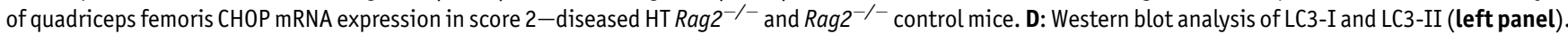
One of three reproducible Western blots and quantification of means \pm SE protein expression levels (right panel) are shown. A value of 1 was arbitrarily assigned to control conditions to which GAPDH were reported and expressed as fold change.

aligned (15 manual landmarks, followed by automatic alignment). Features with only one charge or more than eight charges were excluded from further analyses. After alignment and feature exclusion, the raw abundances of all the features were normalized. Normalization results in a unique factor for each sample that corrects all features in the sample. Statistical analysis was performed using normalized abundances for one-way analysis of variance calculations of all remained features. No minimal thresholds were set for the selection of data to use for quantification. Instead, features presenting $\mathrm{Q}<0.05$ and $P<0.05$ were selected to realize a principal component analysis. MS/MS spectra from selected peptides were exported from the Progenesis LC-MS software as a Mascot Generic file (.mgf) and used for peptide identification with Mascot (version 2.2) in the SwissProt 55.6 (390696 sequences; 140503634 residues) database: Mus musculus 15746 sequences and Homo sapiens 20009 sequences for mice and humans, respectively. The following search parameters were used: $10-\mathrm{ppm}$ peptide mass tolerance and $0.5-\mathrm{Da}$ fragment mass tolerance, one missed cleavage was allowed, carbamidomethylation was set as a fixed modification, and oxidation and deamidation were allowed as variable modifications. Accepting a significance threshold of $P<0.05$, comparison of the search results with the results obtained with a decoy database search allowed estimation of a false discovery rate of approximately $1 \%$ to $2 \%$. For label-free protein quantitation, Mascot results were imported into Progenesis LC-MS software. Similar proteins were grouped, and only nonconflicting features were used for quantitation. To limit further ambiguous interpretation, another step of statistical filtering was applied at the protein level $(P<0.05, \mathrm{Q}<0.05$, and a presenting power value $>0.8)$.

\section{Results}

\section{Forced Expression of $\mathrm{H}-2 \mathrm{~K}^{\mathrm{b}}$ in Muscle Provokes a T-Cell-Independent Myopathy}

Transgenic HT mice were bred onto a Rag $2^{-/}$background so that $\mathrm{H}-2 \mathrm{~K}^{\mathrm{b}}$ could be up-regulated in muscle of immunocompetent (HT) and lymphocyte-deficient (HT Rag $2^{-/}$) animals. After Dox removal at weaning, overexpression of transgenic $\mathrm{H}-2 \mathrm{~K}^{\mathrm{b}}$ mRNA was rapidly observed in skeletal muscle but not in spleen of HT Rag $2^{-/-}$mice (Figure 1). In contrast, endogenous $\mathrm{H}-2 \mathrm{D}^{\mathrm{b}}$ was undetectable in muscle and highly expressed in spleen.

The course of disease was monitored longitudinally. Despite the absence of an adaptive immune system, immunodeficient HT $R a g 2^{-1-}$ mice developed a very severe myopathy that was indistinguishable from that of HT mice. This was manifested by similar survival curves between the groups (Figure 2A) and comparable kinetics of disease occurrence, which, on average, became clinically apparent (score 1) and prominent (score 2) 4 and 6 weeks after $\mathrm{H}-2 \mathrm{~K}^{\mathrm{b}}$ induction, respectively (Figure 2, B and C). Clinical signs were preceded by weight loss (Figure 2D). Myopathy was associated with decreased muscle strength, as measured by a grip strength test (Figure 2E). Hence, forced expression of $\mathrm{H}-2 \mathrm{~K}^{\mathrm{b}}$ in muscle induces a severe myopathy, even in the absence of any possible autoaggressive adaptive immune response.

\section{Histopathologic Features of $\mathrm{H}-2 \mathrm{~K}^{\mathrm{b}}$-Induced Myopathy}

Histologic analysis of muscle sections from score 2diseased mice at different anatomical locations showed signs of chronic nonspecific myopathy with marked variation in 

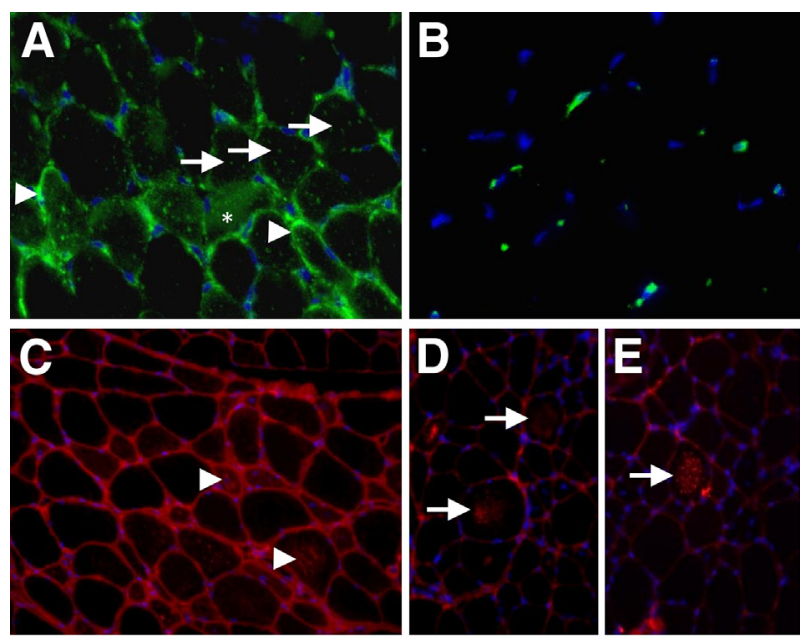

$\mathbf{F}$
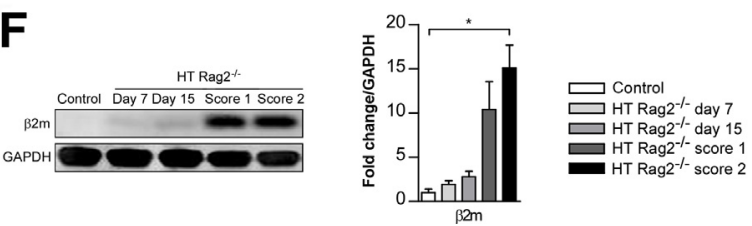

Figure 5 Expression of MHC-I in muscle of diseased mice. A and $\mathbf{B}$ : Gastrocnemius sections from score 2-diseased (A) and control (B) mice were immunostained for $\mathrm{H}-2 \mathrm{~K}^{\mathrm{b}}$ expression. Arrowheads, membrane reexpression; asterisk, intracellular accumulation; arrows, intermyofibrillar deposition. C-E: Immunofluorescence analysis of quadriceps femoris sections from score 2-diseased mice for caveolin (C) or $\alpha \mathrm{B}$-crystallin (D and $\mathbf{E}$ ) expression. C: Ectopic intracellular localization of caveolin (arrowheads). $\mathbf{D}$ and $\mathrm{E}: \alpha \mathrm{B}$-crystallin accumulation (arrows). F: Western blot analysis of $\beta 2$-microglubulin $(\beta 2 \mathrm{~m})$ in muscle of $\mathrm{HT}$ Rag2 $^{-/-}$mice 7 or 15 days after Dox removal and in score $1-$ and score $2-$ diseased HT Rag2 ${ }^{-1-}$ mice. One of three reproducible Western blots and quantification of means \pm SE protein expression levels are shown. A value of 1 was arbitrarily assigned to control conditions to which GAPDH were reported and expressed as fold change. Groups were compared with controls using Student's $t$-test. ${ }^{*} P<0.05$. Original magnification, $\times 200$.

myofiber size, numerous centronucleated fibers, and endomysial fibrosis (Figure 3, A-E). Some peculiar structural changes of diseased myofibers included intermyofibrillar accumulations (Figure 3B); intranuclear eosinophilic inclusions, linear rimmed vacuoles, and massive proteolysis foci (Figure 3C); cytoplasmic bodies (Figure 3D); and myofilamentous degradation areas (Figure 3E). After in vivo injection of Evans blue dye, the presence of numerous fluorescence-positive fibers reflected the extent of myonecrosis (Figure 3F). Electron microscopy further showed accumulation of proteinlike material, vacuoles with granular content resembling autophagic vacuoles, and disruption of myofibrillar architecture (Figure 3G) with myofilament debris (Figure $3 \mathrm{H}$ ). Hence, forced $\mathrm{H}-2 \mathrm{~K}^{\mathrm{b}}$ expression causes a severe myopathy with protein accumulation, vacuolization, and prominent myofiber necrosis and regeneration.

\section{Activation of the UPR in $\mathrm{H}-2 \mathrm{~K}^{\mathrm{b}}$-Induced Myopathy}

To investigate the pathogenic mechanisms of this myopathy, we compared the muscle proteome of score 2-diseased and control mice. For this, we turned to a recent technique of label-free high-resolution protein quantitation. This method allowed very sensitive protein identification at the whole proteome level and excellent quantification of protein abundance.

Forty-five proteins were found to be overrepresented, including the $\mathrm{H}-2 \mathrm{~K}$ transgenic protein, as expected (Table 1). This analysis revealed the up-regulation of different ER stress markers, including the molecular chaperones calreticulin and BiP/GRP78, the latter being a master regulator of the UPR. TRAP1, involved in refolding of denatured proteins after stress and protein degradation, and HSPA2, recognizing nonnative conformations of proteins and participating in ER-associated degradation, seemed to be up-regulated as well.

To confirm involvement of the UPR, we specifically explored some key molecular targets of the UPR. Western blot analysis evidenced up-regulation of ATF6, BiP, calnexin, and $\alpha \mathrm{B}$-crystallin (Figure $4 \mathrm{~A}$ ). They were readily detectable 7 days after induction of $\mathrm{H}-2 \mathrm{~K}^{\mathrm{b}}$ expression and became prominent in score 1-diseased mice (Figure 4A), indicating that occurrence of the UPR precedes clinical manifestations. Spliced but not unspliced XBP1 transcripts were found to be overexpressed (Figure 4B), confirming UPR activation. In addition to the early UPR evidenced by the presence of BiP, ATF6, and spliced XBP1, ER stress-induced proapoptotic CHOP transcripts were found to be up-regulated, indicating that the terminal UPR was also triggered (Figure 4C). Proteome analysis revealed an increase in the lysosomal enzyme cathepsin D, suggesting that some level of autophagy might accompany the UPR (Table 1). Accordingly, Western blot analysis showed overexpression of the main marker of autophagosome maturation LC3-II (Figure 4D).

Together, these results indicate that without involvement of adaptive immunity, overexpression of $\mathrm{H}-2 \mathrm{~K}^{\mathrm{b}}$ in muscle per se causes ER stress that induces the UPR and likely contributes to myofiber death.

\section{ER Stress Is Associated with Intracellular Accumulation of $\mathrm{H}-2 \mathrm{~K}^{\mathrm{b}}$ in Muscle Fibers}

MHC-I molecules are dimeric membrane proteins composed of a heavy chain such as $\mathrm{H}-2 \mathrm{~K}^{\mathrm{b}}$ and $\beta 2$-microglubulin.

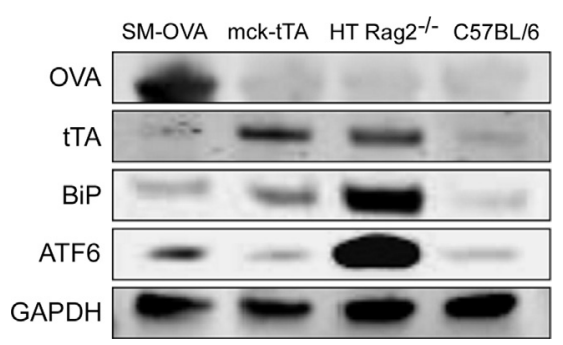

Figure 6 Analysis of the UPR in different muscles of transgenic mice. Western blot analysis of ATF6 and BiP of SM-OVA, mck-tTA, score 2-diseased HT Rag2 $^{-1-}$ mice, and $\mathrm{C} 57 \mathrm{BL} / 6$ controls. One representative Western blot from two reproducible experiments performed in two mice per group are shown. Staining with antibodies against OVA, tTA, and GAPDH were used as controls. 

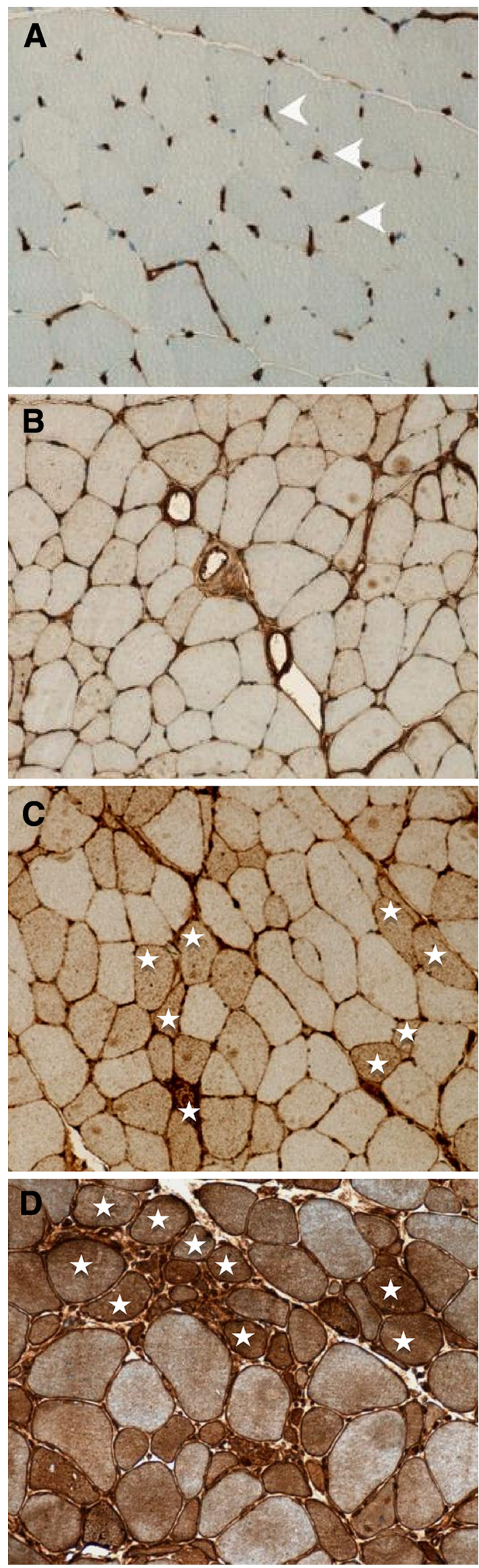

Occurrence of the UPR suggested that owing to high-level transgenic protein production and low $\beta 2$-microglubulin availability, not all $\mathrm{H}-2 \mathrm{~K}^{\mathrm{b}}$ proteins reached the membrane but that some accumulated inside myofibers and caused ER stress. To investigate this possibility, muscle sections were analyzed histologically for $\mathrm{H}-2 \mathrm{~K}^{\mathrm{b}}$ expression. Immunofluorescence analysis showed membrane reexpression (Figure 5A) but also intracellular accumulation and intermyofibrillar deposition of $\mathrm{H}-2 \mathrm{~K}^{\mathrm{b}}$ protein, whereas myofibers from control muscle were negative for $\mathrm{H}-2 \mathrm{~K}^{\mathrm{b}}$, with only capillary immunoreactivity (Figure 5B). This was associated to ectopic intracellular localization of caveolin in addition to its normal sarcolemmal expression (Figure 5C) and to $\alpha \mathrm{B}$-crystallin accumulation (Figure 5, D and E). As expected, we found low levels of $\beta 2$-microglubulin by Western blot analysis early after $\mathrm{H}-2 \mathrm{~K}^{\mathrm{b}}$ induction, whereas it raised dramatically when disease was manifest in score 1- or score 2-diseased animals (Figure 5F). The up-regulation of BiP and ATF6 in HT Rag2 $2^{-/}$mice was neither found in mcktTA single transgenic mice that express only the tTA transgene but not $\mathrm{H}-2 \mathrm{~K}^{\mathrm{b}}$ in muscle nor in SM-OVA mice that express a membrane-bound form of ovalbumin in muscle, ${ }^{32}$ indicating that the mere expression of a transgene does not systematically induce the UPR in muscle (Figure 6). Hence, in HT Rag2 ${ }^{-/-}$mice, part of $\mathrm{H}-2 \mathrm{~K}^{\mathrm{b}}$ cannot reach the membrane and accumulate inside myofibers, causing ER stress.

Intracellular Accumulation of MHC-I Correlates with the UPR in Muscle of Patients with IBM

We aimed to determine whether intracellular accumulation of MHC-I molecules could also be observed in human myositis. We, therefore, analyzed muscle biopsy samples from patients with IBM because surface MHC-I reexpression is a histologic hallmark of this disease and the UPR is suspected of playing a pathogenic role. ${ }^{44,45}$ In humans, normal myofibers were strictly HLA-I negative (Figure 7A), and only endomysial capillaries were stained. As expected, all the patients with IBM had ubiquitous sarcolemmal HLA-I reexpression at the myofiber surface (Figure 7, B-D). Importantly, HLA-I also accumulated in myofibers (Figure 7, C and D) in a manner that was variable from one patient to another. Hence, it was possible to stratify patients according to three levels of intracellular HLA-I accumulation: low (Figure 7B), intermediate (Figure 7C), and high

Figure 7 Immunohistochemical analysis of HLA-I expression in muscle from patients with IBM. Frozen human muscle section after staining with an immunoperoxidase-labeled anti-HLA ABC antibody. Original magnification, $\times 200$. A: Histologically normal muscle (arrowheads indicate endomysial capillaries that physiologically express HLA-I). B-D: Immunohistochemical analysis of muscle biopsy specimens from patients with IBM showing surface reexpression and low (B), intermediate (C), and high (D) accumulation of HLA-I inside myofibers (stars; not all cells with high intracellular accumulation were marked owing to their numbers). 

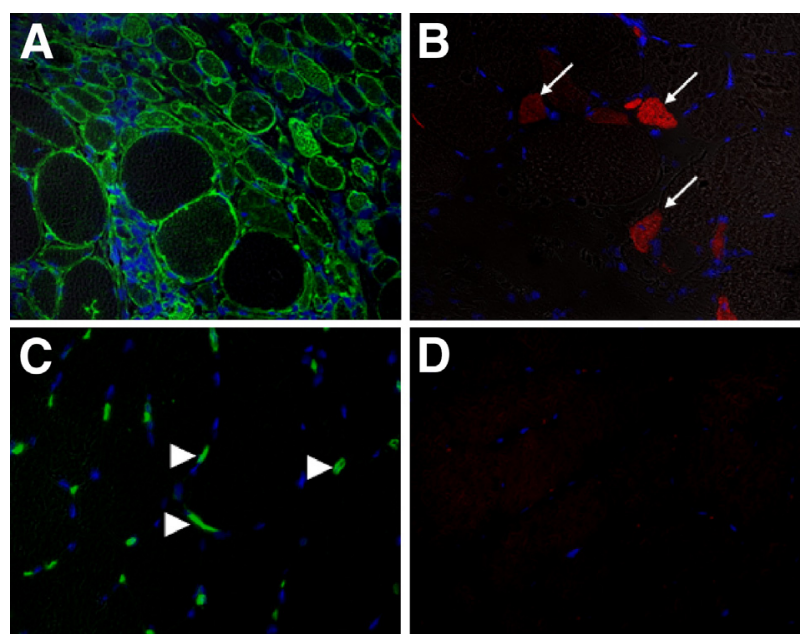

Figure 8 Immunofluorescence analysis of $\mathrm{nMyHC}$ and HLA-I expression in IBM muscle. $\mathbf{A}$ and $\mathbf{B}$ : Muscle with diffuse myofiber HLA-I reexpression. A: Ubiquitous reexpression of HLA-I antigens with sarcolemmal and varied cytoplasmic positive labeling. B: Presence of some small regenerative fibers expressing nMyHC (arrows). C and D: Normal control muscle. C: Lack of HLA-I expression by myofibers with positivities restricted to the endothelial cells of endomysial capillaries (arrowheads). D: Absence of nMyHC expression.

(Figure 7D). Some HLA-I-positive fibers were regenerative, as attested to by their small size, the presence of central nuclei, and expression of the nMyHC (Figure 8).

To evaluate whether intracellular HLA-I accretion could contribute to UPR activation, we analyzed expression levels of UPR molecular targets. First, HLA-I levels correlated with histologic stratification (Figure 9). BiP was found to be augmented twofold in patients with low and intermediate HLA-I levels and fourfold in patients with high HLA-I levels. Calreticulin and HSP90- $\alpha 2$ levels were also found to be increased. Regarding autophagy, Rab1 a and cathepsin D were augmented in patients with high HLA-I levels. Together, these results indicate that the UPR is triggered in IBM as a function of the level of intracellular HLA-I accumulation.

\section{Discussion}

This study demonstrates the direct pathogenicity of MHC-I molecules on muscle independently of their role in adaptive immunity. Indeed, without the involvement of lymphocytes, overexpression of $\mathrm{H}-2 \mathrm{~K}^{\mathrm{b}}$ per se causes an even more severe myopathy than a dystrophin gene mutation, for example. ${ }^{46,47}$ The present results are consistent with the observation of $\mathrm{Li}$ et $\mathrm{al}^{43}$ reporting $50 \%$ lethality of immunocompetent HT mice at day 60 to 70. Histologic analysis revealed pathologic features of nonspecific myopathy with intracellular protein accumulation, vacuolization, and myofiber necrosis/ regeneration (Figure 3). Accumulation of proteinaceous material may proceed from MHC-I accretion but also possibly from myofibrillar degeneration (Figure $3 \mathrm{H}$ ). Highresolution quantitative proteomics confirmed by Western blot analysis revealed ER stress responsible for triggering the
UPR, as attested to by up-regulation of characteristic targets, such as BiP, ATF6, and spliced XBP1, and up-regulation of CHOP, a late marker of the UPR triggering cell death (Figure 4). It is reasonable to assume that the myofiber death observed histologically at least partly depends on induction of this pathway. Subsequently, myofiber death elicits cell regeneration, as evidenced by the presence of centronucleated myofibers (Figure 3). The presence of TRAP1 (Table 1) also suggested intracellular protein ubiquitination in response to stress. ${ }^{48}$ Autophagy was also possibly active in diseased muscle, as evidenced by up-regulation of LC3-I and its conversion into LC3-II, indicating autophagosome maturation (Figure 4D) and increased levels of the lysosome and phagolysosome protein cathepsin D (Table 1). Besides the mechanism evidenced herein, it is possible that other pathologic processes are triggered in response to intracellular accretion of proteins in muscle, as recently shown, for example, in mice transgenic for amyloid precursor protein, whose accumulation in muscle causes structural and functional alterations of mitochondria that precede histopathologic and clinical signs of disease. ${ }^{49}$

Tissue-specific overexpression of transgenic $\mathrm{H}-2 \mathrm{~K}^{\mathrm{b}}$ in immunocompetent animals has previously been reported to provoke thyroid or pancreas damage with little lymphocytic infiltration, ${ }^{50,51}$ suggesting that MHC-I molecules might exert some direct cell cytotoxicty. More recently, Nagaraju et $\mathrm{al}^{42}$ reported evidence of ER stress in immunocompetent HT mice. These findings may have been caused by MHC-I expression itself but may also be influenced by a tissuetargeted immune response. Herein, using immunodeficient mice, we unambiguously demonstrate for the first time that

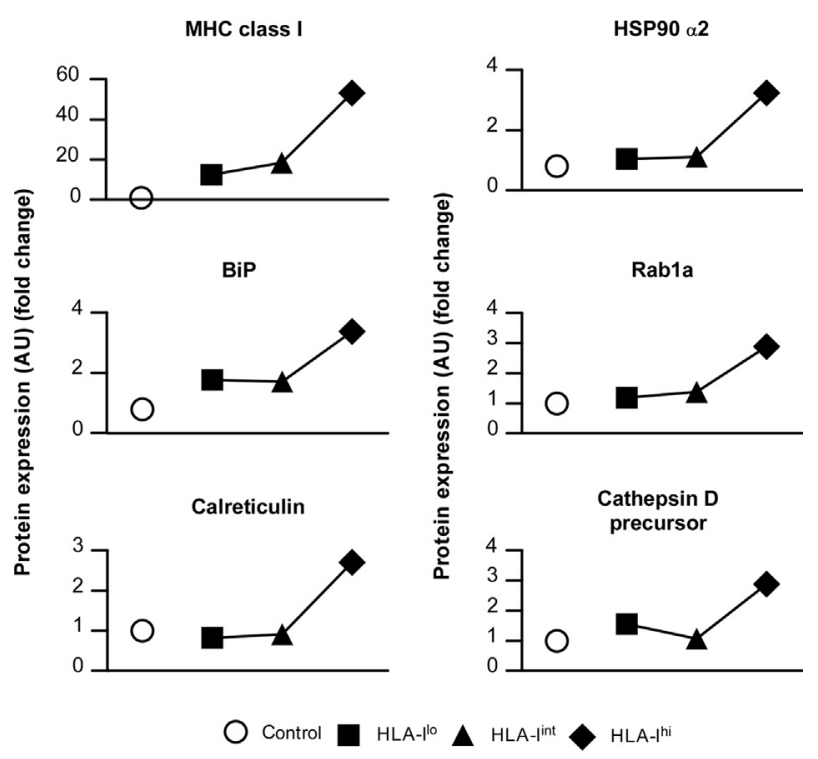

Figure 9 Quantitation of ER stress-associated proteins in muscle of patients with IBM. Expression levels (mean of fold changes, high-resolution quantitation by the Orbitrap method) of proteins characteristic of the UPR and autophagy. Muscle biopsy samples from patients with IBM and low $\left(\right.$ HLA-I $\left.^{\text {lo }}, n=4\right)$, intermediate (HLA-I ${ }^{\text {int }}, n=3$ ), or high (HLA-I ${ }^{\text {hi }}, n=2$ ) cytoplasmic accumulation of MHC-I compared with controls $(n=4)$. 
MHC-I expression is directly toxic for myofibers that are normally MHC-I negative, independent of their capacity to present autoantigens to $\mathrm{T}$ cells.

MHC-I surface expression is $\beta 2$-microglobulin dependent. Herein, part of $\mathrm{H}-2 \mathrm{~K}^{\mathrm{b}}$ is membrane expressed, whereas the remaining accumulates intracellularly (Figure 5A). It is likely that the paucity of $\beta 2$-microglobulin has favored the early intracellular accumulation of $\mathrm{H}-2 \mathrm{~K}^{\mathrm{b}}$, whereas in score 2-diseased mice, $\beta 2$-microglobulin became up-regulated (Figure $5 \mathrm{~F}$ ), possibly through an NF- $\mathrm{KB}$-dependent process, which has been shown to be up-regulated in this model. ${ }^{42}$ Consistently, we found up-regulation of NF- $\kappa \mathrm{B}$ p65 transcripts in score 2-diseased HT Rag $2^{-/-}$mice only (data not shown).

The pathologic findings in HT mice are different from those of IBM in humans. Nevertheless, reexpression of HLA-I is a classical feature of IBM, permitting autoantigen presentation to $\mathrm{CD}^{+} \mathrm{T}$ cells abundantly found in patients' endomysial infiltrates and blood. ${ }^{7}$ Despite this activation of adaptive immunity, IBM remains refractory to immunosuppression $^{25}$ and may, therefore, not be primarily autoimmune but rather akin to Alzheimer disease with amyloid protein and phosphorylated tau aggregates. ${ }^{23}$ This resistance to immunosuppressive therapy is likely linked to this degenerative nature of IBM. Indeed, although prednisone and intravenous Igs reduce muscle inflammation, they have no effect on the level of amyloid precursor protein in IBM muscle. ${ }^{52}$ This contrasts with other situations, such as polymyositis, which is generally sensitive to corticosteroid therapy because of its primary autoimmune nature involving an autoaggressive cytotoxic T-cell response against muscle. ${ }^{53}$ Although requiring a stronger immunosuppressive regimen, necrotizing autoimmune myopathies are also generally sensitive to therapy, presumably because they involve a primary immune pathogenesis with complement deposition in muscle and autoantibodies whose titers are correlated with disease severity. ${ }^{14}$ We show herein that the ER stress pathways and intracellular accumulation of MHC-I molecules are also present in IBM muscle (Figure 7). For this, we used the precise quantification allowed by the Orbitrap method, which requires only a limited amount of protein extract and permits the analysis of different proteins at the same time. We show, for the first time, that the intensity of the UPR is linked to the degree of intrafiber accumulation of HLA-I molecules (Figure 9) and not merely to their presence at the cell surface. Hence, it is reasonable to relate HLA-I accumulation to ER stress pathways in IBM. This does not exclude the participation of $\mathrm{CD}^{+} \mathrm{T}$ cells that could perpetuate HLA-I expression through a cytokinedependent process.

Different myopathies with reexpression of MHC-I may be associated or not with lymphocytic infiltrates. This reflects the fact that MHC-I is necessary but not sufficient to elicit a durable $\mathrm{CD} 8^{+} \mathrm{T}$-cell response in situ, which requires the presence of muscle-reactive cells in the T-cell repertoire, their homing to the target tissue, and their maintenance in the muscle environment. We recently showed in mice that specific $\mathrm{CD}^{+} \mathrm{T}$ cells that recognize a muscle-expressed neo-autoantigen are actively purged from the repertoire by a mechanism of peripheral deletion. ${ }^{33}$ It is possible that this process may be differentially defective in different forms of myopathy, allowing or disallowing the presence of musclereactive $\mathrm{T}$ cells that could respond to autoantigens presented by MHC-I when reexpressed by muscle in the immune system. Depending on the disease, myopathies may also be associated with different local levels of cytokines and chemokines that are required for homing and penetration of autoantigen-reactive $\mathrm{T}$ cells in muscle. Furthermore, we recently showed that a mechanical muscle injury provokes local reexpression of MHC-I and activation of antigenspecific $\mathrm{T}$ cells in the draining lymph nodes but only a transient muscle $\mathrm{CD}^{+}$T-cell infiltrate, reflecting the existence of immunoregulatory mechanisms that prevent the maintenance of $\mathrm{T}$ cells in the muscle tissue ${ }^{34}$ consistent with what has also earlier been observed in the myocardium. ${ }^{54}$ It can be hypothesized that the peripheral mechanisms that counteract T-cell survival in muscle may be differentially affected in different forms of myopathy in which reexpression of MHC-I is otherwise observed.

In summary, intracellular accumulation of transgenic $\mathrm{H}-2 \mathrm{~K}^{\mathrm{b}}$ with limited $\beta 2$-microglobulin availability in HT mice elicits ER stress with induction of the UPR, causing severe myopathy with myofiber death and subsequent regeneration. This phenomenon occurs independent of the immune function of MHC-I to present antigen to T cells. In IBM, amyloid protein aggregates but also HLA-I seemingly elicit the UPR that contributes to myofiber death. Regenerating fibers express HLA-I, which may present autoantigens to $\mathrm{CD}^{+} \mathrm{T}$ cells that, in turn, perpetuate HLA-I overproduction. Therefore, targeting UPR pathways may represent a therapeutic strategy for IBM.

\section{Acknowledgments}

We thank Alice Marchand, Carole Bonneau, Laetitia Jean, and Yann Lacoume for animal care and/or genotyping of animals; Jenny Ho for help in performing LC-MS/MS experiments using the LTQ-Orbitrap Velos; and Sébastien Calbo for advice and helpful discussions.

\section{References}

1. Bohan A, Peter JB: Polymyositis and dermatomyositis (first of two parts). N Engl J Med 1975, 292:344-347

2. Bohan A, Peter JB: Polymyositis and dermatomyositis (second of two parts). N Engl J Med 1975, 292:403-407

3. Bender A, Ernst N, Iglesias A, Dornmair K, Wekerle H, Hohlfeld R: $\mathrm{T}$ cell receptor repertoire in polymyositis: clonal expansion of autoaggressive CD8+ T cells. J Exp Med 1995, 181:1863-1868

4. Benveniste O, Cherin P, Maisonobe T, Merat R, Chosidow O, Mouthon L, Guillevin L, Flahault A, Burland MC, Klatzmann D, Herson S, Boyer O: Severe perturbations of the blood T cell repertoire 
in polymyositis, but not dermatomyositis patients. J Immunol 2001, 167:3521-3529

5. Greenberg SA, Pinkus JL, Pinkus GS, Burleson T, Sanoudou D, Tawil R, Barohn RJ, Saperstein DS, Briemberg HR, Ericsson M, Park P, Amato AA: Interferon-alpha/beta-mediated innate immune mechanisms in dermatomyositis. Ann Neurol 2005, 57:664-678

6. Bender A, Behrens L, Engel AG, Hohlfeld R: T-cell heterogeneity in muscle lesions of inclusion body myositis. J Neuroimmunol 1998, 84: 86-91

7. Dimitri D, Benveniste O, Dubourg O, Maisonobe T, Eymard B, Amoura Z, Jean L, Tiev K, Piette JC, Klatzmann D, Herson S, Boyer O: Shared blood and muscle CD8+ T-cell expansions in inclusion body myositis. Brain 2006, 129:986-995

8. Griggs RC, Askanas V, DiMauro S, Engel A, Karpati G, Mendell JR, Rowland LP: Inclusion body myositis and myopathies. Ann Neurol 1995, 38:705-713

9. Mammen AL: Autoimmune myopathies: autoantibodies, phenotypes and pathogenesis. Nat Rev Neurol 2011, 7:343-354

10. Troyanov Y, Targoff IN, Tremblay JL, Goulet JR, Raymond Y, Senecal JL: Novel classification of idiopathic inflammatory myopathies based on overlap syndrome features and autoantibodies: analysis of 100 French Canadian patients. Medicine (Baltimore) 2005, 84: 231-249

11. Ohosone $\mathrm{Y}$, Ishida M, Takahashi Y, Matsumura M, Hirakata M, Kawahara Y, Nishikawa T, Mimori T: Spectrum and clinical significance of autoantibodies against transfer RNA. Arthritis Rheum 1998, $41: 1625-1631$

12. Targoff IN: Laboratory testing in the diagnosis and management of idiopathic inflammatory myopathies. Rheum Dis Clin North Am 2002, 28:859-890, viii

13. Hoogendijk JE, Amato AA, Lecky BR, Choy EH, Lundberg IE, Rose MR, Vencovsky J, de Visser M, Hughes RA: 119th ENMC international workshop: trial design in adult idiopathic inflammatory myopathies, with the exception of inclusion body myositis, 10-12 October 2003. Naarden, The Netherlands. Neuromuscul Disord 2004, 14:337-345

14. Benveniste O, Drouot L, Jouen F, Charuel JL, Bloch-Queyrat C, Behin A, Amoura Z, Marie I, Guiguet M, Eymard B, Gilbert D, Tron F, Herson S, Musset L, Boyer O: Correlation of anti-signal recognition particle autoantibody levels with creatine kinase activity in patients with necrotizing myopathy. Arthritis Rheum 2011, 63:1961-1971

15. Mammen AL, Chung T, Christopher-Stine L, Rosen P, Rosen A, Doering KR, Casciola-Rosen LA: Autoantibodies against 3-hydroxy3-methylglutaryl-coenzyme A reductase in patients with statinassociated autoimmune myopathy. Arthritis Rheum 2011, 63: 713-721

16. Hohlfeld R, Engel AG: HLA expression in myoblasts. Neurology 1991, 41:2015

17. Appleyard ST, Dunn MJ, Dubowitz V, Rose ML: Increased expression of HLA ABC class I antigens by muscle fibres in Duchenne muscular dystrophy, inflammatory myopathy, and other neuromuscular disorders. Lancet 1985, 1:361-363

18. McDouall RM, Dunn MJ, Dubowitz V: Expression of class I and class II MHC antigens in neuromuscular diseases. J Neurol Sci 1989, 89:213-226

19. Emslie-Smith AM, Arahata K, Engel AG: Major histocompatibility complex class I antigen expression, immunolocalization of interferon subtypes, and $\mathrm{T}$ cell-mediated cytotoxicity in myopathies. Hum Pathol 1989, 20:224-231

20. Confalonieri P, Oliva L, Andreetta F, Lorenzoni R, Dassi P, Mariani E, Morandi L, Mora M, Cornelio F, Mantegazza R: Muscle inflammation and MHC class I up-regulation in muscular dystrophy with lack of dysferlin: an immunopathological study. J Neuroimmunol 2003, 142:130-136

21. Salaroli R, Baldin E, Papa V, Rinaldi R, Tarantino L, De Giorgi LB, Fusconi M, Malavolta N, Meliconi R, D'Alessandro R, Cenacchi G: Validity of internal expression of the major histocompatibility complex class I in the diagnosis of inflammatory myopathies. J Clin Pathol 2012, 65:14-19

22. Pavlath GK: Regulation of class I MHC expression in skeletal muscle: deleterious effect of aberrant expression on myogenesis. J Neuroimmunol 2002, 125:42-50

23. Askanas V, Engel WK: Inclusion-body myositis: a myodegenerative conformational disorder associated with Abeta, protein misfolding, and proteasome inhibition. Neurology 2006, 66:S39-S48

24. Greenberg SA, Sanoudou D, Haslett JN, Kohane IS, Kunkel LM, Beggs AH, Amato AA: Molecular profiles of inflammatory myopathies. Neurology 2002, 59:1170-1182

25. Benveniste O, Guiguet M, Freebody J, Dubourg O, Squier W, Maisonobe T, Stojkovic T, Leite MI, Allenbach Y, Herson S, Brady S, Eymard B, Hilton-Jones D: Long-term observational study of sporadic inclusion body myositis. Brain 2011, 134: $3176-3184$

26. Amato AA, Barohn RJ: Inclusion body myositis: old and new concepts. J Neurol Neurosurg Psychiatry 2009, 80:1186-1193

27. Greenberg SA: Theories of the pathogenesis of inclusion body myositis. Curr Rheumatol Rep 2010, 12:221-228

28. Katsumata Y, Ascherman DP: Animal models in myositis. Curr Opin Rheumatol 2008, 20:681-685

29. Nagaraju K, Plotz PH: Animal models of myositis. Rheum Dis Clin North Am 2002, 28:917-933

30. Allenbach Y, Solly S, Gregoire S, Dubourg O, Salomon B, ButlerBrowne G, Musset L, Herson S, Klatzmann D, Benveniste O: Role of regulatory $\mathrm{T}$ cells in a new mouse model of experimental autoimmune myositis. Am J Pathol 2009, 174:989-998

31. Katsumata Y, Harigai M, Sugiura T, Kawamoto M, Kawaguchi $Y$, Matsumoto Y, Kohyama K, Soejima M, Kamatani N, Hara M: Attenuation of experimental autoimmune myositis by blocking ICOSICOS ligand interaction. J Immunol 2007, 179:3772-3779

32. Calbo S, Delagreverie H, Arnoult C, Authier FJ, Tron F, Boyer O: Functional tolerance of $\mathrm{CD} 8+\mathrm{T}$ cells induced by muscle-specific antigen expression. J Immunol 2008, 181:408-417

33. Franck E, Bonneau C, Jean L, Henry JP, Lacoume Y, Salvetti A, Boyer O, Adriouch S: Immunological tolerance to muscle autoantigens involves peripheral deletion of autoreactive $\mathrm{CD} 8+\mathrm{T}$ cells. PLoS One 2012, 7:e36444

34. Liao H, Franck E, Freret M, Adriouch S, Baba-Am Y, Authier FJ, Boyer O, Gherardi RK: Myoinjury transiently activates muscle antigen-specific CD8 $+\mathrm{T}$ cells in lymph nodes in a mouse model. Arthritis Rheum 2012, 64:3441-3451

35. Fukuchi K, Pham D, Hart M, Li L, Lindsey JR: Amyloid-beta deposition in skeletal muscle of transgenic mice: possible model of inclusion body myopathy. Am J Pathol 1998, 153:1687-1693

36. Jin LW, Hearn MG, Ogburn CE, Dang N, Nochlin D, Ladiges WC, Martin GM: Transgenic mice over-expressing the C-99 fragment of betaPP with an alpha-secretase site mutation develop a myopathy similar to human inclusion body myositis. Am J Pathol 1998, 153:1679-1686

37. Sugarman MC, Yamasaki TR, Oddo S, Echegoyen JC, Murphy MP, Golde TE, Jannatipour M, Leissring MA, LaFerla FM: Inclusion body myositis-like phenotype induced by transgenic overexpression of beta APP in skeletal muscle. Proc Natl Acad Sci U S A 2002, 99: 6334-6339

38. Prevot N, Briet C, Lassmann H, Tardivel I, Roy E, Morin J, Mak TW, Tafuri A, Boitard C: Abrogation of ICOS/ICOS ligand costimulation in NOD mice results in autoimmune deviation toward the neuromuscular system. Eur J Immunol 2010, 40:2267-2276

39. Bittner RE, Anderson LV, Burkhardt E, Bashir R, Vafiadaki E, Ivanova S, Raffelsberger T, Maerk I, Hoger H, Jung M, Karbasiyan M, Storch M, Lassmann H, Moss JA, Davison K, Harrison R, Bushby KM, Reis A: Dysferlin deletion in SJL mice (SJL-Dysf) defines a natural model for limb girdle muscular dystrophy 2B. Nat Genet 1999, 23:141-142

40. Nagaraju K, Raben N, Loeffler L, Parker T, Rochon PJ, Lee E, Danning C, Wada R, Thompson C, Bahtiyar G, Craft J, Hooft Van 
Huijsduijnen R, Plotz P: From the cover: conditional up-regulation of MHC class I in skeletal muscle leads to self-sustaining autoimmune myositis and myositis-specific autoantibodies. Proc Natl Acad Sci U S A 2000, 97:9209-9214

41. Coley W, Rayavarapu S, Pandey GS, Sabina RL, Van der Meulen JH, Ampong B, Wortmann RL, Rawat R, Nagaraju K: The molecular basis of skeletal muscle weakness in a mouse model of inflammatory myopathy. Arthritis Rheum 2012, 64:3750-3759

42. Nagaraju K, Casciola-Rosen L, Lundberg I, Rawat R, Cutting S, Thapliyal R, Chang J, Dwivedi S, Mitsak M, Chen YW, Plotz P, Rosen A, Hoffman E, Raben N: Activation of the endoplasmic reticulum stress response in autoimmune myositis: potential role in muscle fiber damage and dysfunction. Arthritis Rheum 2005, 52:1824-1835

43. Li CK, Knopp P, Moncrieffe H, Singh B, Shah S, Nagaraju K, Varsani H, Gao B, Wedderburn LR: Overexpression of MHC class I heavy chain protein in young skeletal muscle leads to severe myositis: implications for juvenile myositis. Am J Pathol 2009, 175:1030-1040

44. Askanas V, Engel WK, Nogalska A: Inclusion body myositis: a degenerative muscle disease associated with intra-muscle fiber multi-protein aggregates, proteasome inhibition, endoplasmic reticulum stress and decreased lysosomal degradation. Brain Pathol 2009, 19:493-506

45. Vattemi G, Engel WK, McFerrin J, Askanas V: Endoplasmic reticulum stress and unfolded protein response in inclusion body myositis muscle. Am J Pathol 2004, 164:1-7

46. Dangain J, Vrbova G: Muscle development in mdx mutant mice. Muscle Nerve 1984, 7:700-704

47. Tanabe Y, Esaki K, Nomura T: Skeletal muscle pathology in X chromosome-linked muscular dystrophy $(\mathrm{mdx})$ mouse. Acta Neuropathol 1986, 69:91-95
48. Amoroso MR, Matassa DS, Laudiero G, Egorova AV, Polishchuk RS, Maddalena F, Piscazzi A, Paladino S, Sarnataro D, Garbi C, Landriscina M, Esposito F: TRAP1 and the proteasome regulatory particle TBP7/Rpt3 interact in the endoplasmic reticulum and control cellular ubiquitination of specific mitochondrial proteins. Cell Death Differ 2012, 19:592-604

49. Boncompagni S, Moussa CE, Levy E, Pezone MJ, Lopez JR, Protasi F, Shtifman A: Mitochondrial dysfunction in skeletal muscle of amyloid precursor protein-overexpressing mice. J Biol Chem 2012, 287:20534-20544

50. Allison J, Campbell IL, Morahan G, Mandel TE, Harrison LC, Miller JF: Diabetes in transgenic mice resulting from over-expression of class I histocompatibility molecules in pancreatic beta cells. Nature 1988, 333:529-533

51. Turnley AM, Morahan G, Okano H, Bernard O, Mikoshiba K, Allison J, Bartlett PF, Miller JF: Dysmyelination in transgenic mice resulting from expression of class I histocompatibility molecules in oligodendrocytes. Nature 1991, 353:566-569

52. Zschuntzsch J, Voss J, Creus K, Sehmisch S, Raju R, Dalakas MC, Schmidt J: Provision of an explanation for the inefficacy of immunotherapy in sporadic inclusion body myositis: quantitative assessment of inflammation and beta-amyloid in the muscle. Arthritis Rheum 2012, 64:4094-4103

53. Dalakas MC: Therapeutic approaches in patients with inflammatory myopathies. Semin Neurol 2003, 23:199-206

54. Grabie N, Gotsman I, DaCosta R, Pang H, Stavrakis G, Butte MJ, Keir ME, Freeman GJ, Sharpe AH, Lichtman AH: Endothelial programmed death-1 ligand 1 (PD-L1) regulates CD8+ T-cell mediated injury in the heart. Circulation 2007, 116:2062-2071 